\title{
Off-pump versus on-pump: State of the ART?
}

\author{
Edward Y. Sako, MD, PhD
}

\footnotetext{
From the Department of Cardiothoracic Surgery, University of Texas Health Science Center at San Antonio, San Antonio, Tex.

Disclosures: Dr Sako has a financial relationship with Medtronic, Inc.

Received for publication Nov 8, 2017; accepted for publication Nov 9, 2017; available ahead of print Dec 14, 2017.

Address for reprints: Edward Y. Sako, MD, PhD, Department of Cardiothoracic Surgery, University of Texas Health Science Center at San Antonio, Mail Code 7841, 7703 Floyd Curl Dr, San Antonio, TX 78229-3900 (E-mail: sako@uthscsa.edu).

J Thorac Cardiovasc Surg 2018;155:1554

$0022-5223 / \$ 36.00$

Copyright $(\underset{c}{ } 2017$ by The American Association for Thoracic Surgery

https://doi.org/10.1016/j.jtcvs.2017.11.020
}

The Arterial Revascularization Trial (ART) was designed to look at long-term survival of patients undergoing bilateral internal thoracic artery grafting versus those receiving a single internal thoracic artery graft in addition to saphenous vein grafts. In the accompanying article, Benedetto and colleagues $^{1}$ have done a post hoc analysis of the ART data, looking at a comparison of cases done on- versus off-pump. As a multicenter cooperative trial, more than 3000 patients were enrolled across 28 hospitals and 7 countries. A total of 156 surgeons were involved, although a large number of them performed a small number of procedures. The decision for on- versus off-pump was left to the surgeon's discretion. Mean follow-up was 5 years and complete for $96 \%$ of the patients. A propensitymatched analysis was used. The major findings included no significant difference between the off-pump and onpump groups with regard to in-hospital mortality, 5-year mortality, and major adverse cardiovascular and cerebrovascular events.

This is another in a series of the ongoing debate over onversus off-pump coronary artery bypass grafting. Before considering the conclusion and impact of this study, several points need to be made. The first is that one should be cautious about interpreting data in a post hoc analysis of a larger study that was not originally designed to look at that particular topic. There may be inherent bias or problems with data collection that were not accounted for, as the original study was not designed to answer the question at hand. In this particular study, patient and surgeon selection are keys to interpreting the results. As noted by the authors, most of the off-pump procedures were done by 3 almost purely off-pump surgeons, and most of the on-pump surgeries were done by 95 surgeons

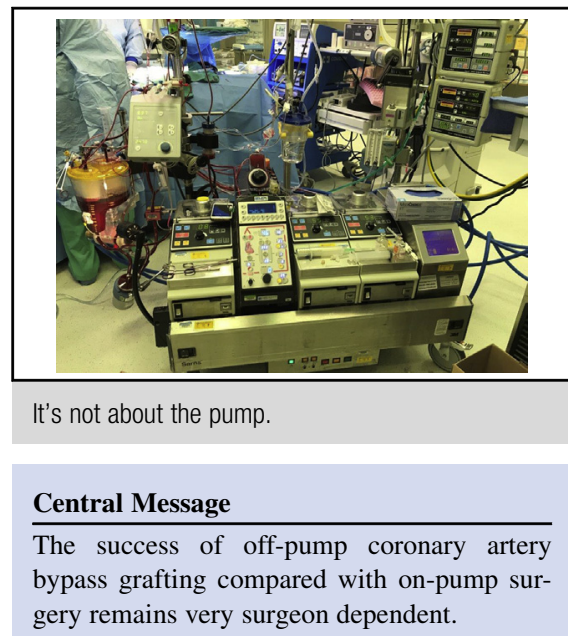

See Article page 1545.

performing exclusively on-pump. In other words, few surgeons did significant numbers of both surgeries. It was also noted that off-pump cases done by "sporadic" offpump surgeons had a greater operative mortality.

These results are therefore less about the technique and probably more about the surgeon. Those who either have not had much experience in off-pump surgery or tried and have abandoned the procedure (an increasing number ${ }^{2}$ ) may not be able to replicate the results. Therefore, the conclusion of the study is incomplete. It should also include the provision as stated in the discussion, "...supports the central role of surgeon expertise in determining short- and long-term results after off-pump." It is becoming clear that off-pump coronary artery bypass grafting can be done with results equivalent to on-pump surgery but only in the hands of those who are experienced and committed to the technique with a high frequency of use.

\section{References}

1. Benedetto, et al. Off-pump versus on-pump coronary artery bypass grafting: insights from the Arterial Revascularization Trial. J Thorac Cardiovasc Surg. 2018; $155: 1545-53$.

2. Bakeen FG, Shroyer AL, Gammie JS, Sabik JF, Cornwell LD, Coselli JS, et al. Trends in the use of off-pump coronary artery bypass grafting: results from the Society of Thoracic Surgeons Adult Cardiac Surgery Database. J Thorac Cardiovasc Surg. 2014;148:856-64. 